Open Access

\title{
Perioperative stroke in patients undergoing elective spinal surgery: a retrospective analysis using the Japanese diagnosis procedure combination database
}

Junichi Ohya ${ }^{1 *}$, Hirotaka Chikuda ${ }^{1}$, Takeshi Oichi ${ }^{1}$, Hiromasa Horiguchi ${ }^{2}$, Katsushi Takeshita', Sakae Tanaka ${ }^{1}$ and Hideo Yasunaga ${ }^{2}$

\begin{abstract}
Background: Although a few studies on perioperative stroke following spinal surgery have been reported, differences in the incidence of perioperative stroke among various surgical procedures have not been determined. The purpose of this retrospective analysis was to investigate the incidence of perioperative stroke during hospitalization in patients undergoing elective spinal surgery, and to examine whether the incidence varied according to the surgical procedure.

Methods: A retrospective analysis of data from the Diagnosis Procedure Combination database, a nationwide administrative impatient database in Japan, identified 167,106 patients who underwent elective spinal surgery during 2007-2012. Patient information extracted included age, sex, preoperative comorbidity, administration of blood transfusion, length of hospitalization, and type of hospital. Clinical outcomes included perioperative stroke during hospitalization, and in-hospital death.

Results: The overall incidence of perioperative stroke was $0.22 \%(371 / 167,106)$ during hospitalization. A logistic regression model fitted with a generalized estimating equation showed perioperative stroke was associated with advanced age, a history of cardiac disease, an academic institution, and resection of a spinal tumor. Patients who underwent resection of a spinal cord tumor (reference) had a higher risk of stroke compared with those undergoing discectomy (odds ratio (OR), 0.29; $95 \%$ confidence interval $(C \mathrm{Cl}), 0.14-0.58 ; p=0.001)$, decompression surgery (OR, 0.44; $95 \% \mathrm{Cl}, 0.26-0.73 ; p=0.001)$, or arthrodesis surgery (OR, $0.55 ; 95 \% \mathrm{Cl}, 0.34-0.90) ; p=0.02)$. Advanced age ( $\geq 80$ years; $\mathrm{OR}, 5.66 ; 95 \% \mathrm{Cl}, 3.10-10.34 ; p \leq 0.001)$, history of cardiac disease (OR, 1.58; $95 \% \mathrm{Cl}, 1.10-2.26 ; p=0.01)$, diabetes (OR, $1.73 ; 95 \% \mathrm{Cl}, 1.36-2.20 ; p \leq 0.001)$, hypertension (OR, 1.53; $95 \% \mathrm{Cl}, 1.18-1.98 ; p=0.001)$, cervical spine surgery (OR, 1.44; $95 \% \mathrm{Cl}, 1.09-1.90 ; p=0.01)$, a teaching hospital $(\mathrm{OR}, 1.36 ; 95 \% \mathrm{Cl}, 1.01-1.82 ; p=0.04)$, and length of stay (OR, 1.008; $95 \% \mathrm{Cl}, 1.005-1.010 ; p \leq 0.001$ ) were also risk factors for perioperative stroke.

Conclusions: Perioperative stroke occurred in $0.22 \%$ of patients undergoing spinal surgery. Resection of a spinal cord tumor was associated with increased risk of perioperative stroke as well as advanced age, comorbidities at admission, cervical spine surgery, surgery in a teaching hospital, and length of stay.
\end{abstract}

Keywords: Perioperative stroke, Database, Spinal cord tumor, Hemorrhagic stroke, Ischemic stroke

\footnotetext{
* Correspondence: oyaj-ort@h.u-tokyo.ac.jp

'Department of Orthopaedic Surgery, Faculty of Medicine, The University of

Tokyo, Hongo 7-3-1, Bunkyo, Tokyo, Japan

Full list of author information is available at the end of the article
}

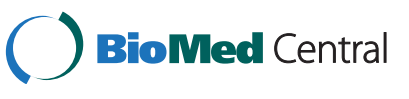

(c) 2015 Ohya et al. Open Access This article is distributed under the terms of the Creative Commons Attribution 4.0 International License (http://creativecommons.org/licenses/by/4.0/), which permits unrestricted use, distribution, and reproduction in any medium, provided you give appropriate credit to the original author(s) and the source, provide a link to the Creative Commons license, and indicate if changes were made. The Creative Commons Public Domain Dedication waiver (http://creativecommons.org/publicdomain/zero/1.0/) applies to the data made available in this article, unless otherwise stated. 


\section{Background}

Perioperative stroke is a rare but devastating complication which can lead to prolonged hospital stay, persistent neurological impairment, and even death [1-3]. The majority of perioperative strokes are classified as ischemic stroke [4-6], though hemorrhagic strokes have also been reported. Known risk factors for perioperative stroke include advanced age, history of stroke, carotid stenosis, and atherosclerosis of the ascending aorta [1, 3, 5, 7-12]. The risk of perioperative stroke is also known to vary according to the type and complexity of the surgical procedure [3, 8, 10, 13-16].

Despite its significant impact on clinical outcomes, the available information on perioperative strokes following spinal surgery is limited, presumably owing to its rarity [17-21]. Although recent studies estimated the incidence to be $0.05-0.1 \%[17,18]$, the precise incidence remains unclear. In addition, the pathomechanism of perioperative stroke following spinal surgery remains largely unknown. Although a possible association between postoperative intracranial hemorrhage and cerebrospinal fluid (CSF) leakage subsequent to durotomy has been discussed in several case reports [17, 22-26], this remains to be established.

The purposes of this retrospective analysis using a Japanese national administrative database were: 1) to investigate the incidence of perioperative stroke during hospitalization in patients undergoing elective spinal surgery; and 2) to examine whether its incidence varies among different surgical procedures. We hypothesized that the procedures requiring durotomy (i.e., the resection of spinal tumor) would carry increased risk of perioperative stroke compared with the other procedures.

\section{Methods}

\section{Data source}

This study used data from the Japanese Diagnosis Procedure Combination (DPC) database [27-32], which includes administrative claims data and discharge abstract data from hospitals across Japan. All 82 university hospitals are obliged to contribute to this system, but adoption by community hospitals is voluntary. In 2011, approximately $50 \%$ of all acutecare admissions in Japan were included in the DPC. The database includes the following information: unique identifier of the hospital and type of hospital (teaching or non-teaching); patient age and sex; main diagnoses; surgical procedures; comorbidities at admission and complications after admission recorded according to the International Classification of Diseases, $10^{\text {th }}$ Revision (ICD-10) codes; length of stay; and in-hospital death. Preexisting comorbidities at admission and complications occurring after admission are recorded separately in the DPC database. The anonymous nature of the data allowed the requirement for informed consent to be waived. Study approval was obtained from the Institutional Review Board of The University of Tokyo.

\section{Patient selection and data}

We extracted patient data from the DPC for the period July 1, 2007 to March 31, 2012 for a total of 39 months: July 1 to December 31 of 2007-2010, January 1 to December 31 of 2011, and January 1 to March 31 of 2012 (DPC data were compiled in collaboration with the Ministry of Health, Labour and Welfare between July and December in 2007-2010 and have been compiled throughout the year since January 2011). We included patients aged 20 years or older who underwent elective spinal surgery (discectomy, decompression surgery, fusion surgery, resection of a spinal cord tumor). Patients requiring emergency admission and patients with a metastatic spinal tumor as the primary diagnosis were excluded from the study. The site of surgery was classified as cervical, thoracic, and lumbosacral. We assessed the patients' clinical characteristics, including age, sex, comorbidities at admission, blood transfusion, length of stay, and type of hospital. Comorbidities at admission included a history of cardiac disease (angina, myocardial infarction, and heart failure), diabetes, hypertension, and a history of stroke.

\section{Outcomes}

The outcomes included perioperative stroke (ICD-10 codes: I60-63) during hospitalization and in-hospital death. We further classified strokes into two categories: hemorrhagic (I60-62) and ischemic (I63).

\section{Statistical analyses}

Continuous variables were compared using analyses of variance or the Kruskal-Wallis test, as appropriate, and proportions were compared using the Chi-square test or Fisher's exact test. Multivariate logistic regression analysis was performed to determine factors associated with the occurrence of perioperative stroke. Because the data were clustered hierarchically (hospital and patient levels), we fitted the regression model with a generalized estimation equation to adjust for within-hospital clustering [33]. Variables that exhibited a significant difference in the univariate analysis were entered into a multivariate logistic regression analysis. The predefined significance for inclusion in the next step of the regression model was $p \leq 0.10$. All statistical analysis were conducted using IBM SPSS version 19.0 (IBM Corp., Armonk, NY, USA). The threshold for significance was a $p$-value $<0.05$. 


\section{Results}

A total of 167,106 patients were identified ( 98,445 male, 68,661 female). The mean age was 64.1 years (range, 20 to 101 years). The most common surgical procedure was decompression surgery (84,540 patients; $50.6 \%)$, followed by arthrodesis surgery (52,784; $31.6 \%)$, discectomy $(24,595 ; 14.7 \%)$, and resection of a spinal cord tumor (5187; $3.1 \%)$. The most common surgical level was lumbar $(109,669 ; 65.6 \%)$. Table 1 presents the characteristics of the study participants according to the surgical procedures.

Overall, perioperative stroke occurred in 371 patients $(0.22 \%)$ during hospitalization (Table 2). Of these, hemorrhagic stroke occurred in 53 patients $(14.2 \%)$ and ischemic stroke in 318 patients (85.7 \%). Eighteen patients died of stroke and the case-fatality rate was $4.9 \%(18 / 371)$.

Table 3 shows the results of the multivariate logistic regression analysis for perioperative stroke. Perioperative stroke was associated with resection of a spinal tumor. Patients who underwent resection of a spinal cord tumor (reference) had a higher risk of stroke compared with those undergoing discectomy (odds ratio
(OR), 0.29; $95 \%$ confidence interval (CI), 0.14-0.58; $p=0.001$ ), decompression surgery (OR, 0.44; $95 \% \mathrm{CI}$, $0.26-0.73 ; p=0.001$ ), or arthrodesis surgery (OR, 0.55 ; $95 \%$ CI, 0.34-0.90); $p=0.02$ ). Advanced age ( $\geq 80$ years; OR, 5.66; $95 \%$ CI, 3.10-10.34; $p \leq 0.001$ ), a history of cardiac disease (OR, 1.58; $95 \% \mathrm{CI}, 1.10-2.26 ; p=0.01)$, diabetes (OR, 1.73; $95 \% \mathrm{CI}, 1.36-2.20 ; p \leq 0.001$ ), hypertension (OR, 1.53; $95 \% \mathrm{CI}, 1.18-1.98 ; p=0.001)$, cervical spine surgery (OR, 1.44; $95 \% \mathrm{CI}, 1.09-1.90$; $p=0.01$ ), surgery in a teaching hospital (OR, 1.36; $95 \% \mathrm{CI}$, $1.01-1.82 ; p=0.04)$, and length of stay (OR, 1.008; $95 \% \mathrm{CI}$, $1.005-1.010 ; p \leq 0.001)$ were also identified as risk factors for perioperative stroke.

We further examined the proportion of hemorrhagic stroke among perioperative stroke in every surgical procedure. Among perioperative stroke, the proportion of hemorrhagic stroke following elective spinal surgery was $14.3 \%$ (53/371). The proportion of hemorrhagic stroke among perioperative stroke following resection of a spinal tumor was $36.8 \%$ (7/19), which was significantly higher compared with other procedures (vs 46/352, $p=0.01$, Fisher's exact test).

Table 1 Characteristics of the study population according to surgical procedures ( $N(\%))$

\begin{tabular}{|c|c|c|c|c|c|c|c|c|c|c|c|}
\hline \multirow[b]{2}{*}{ Age, years; mean [SD] } & \multicolumn{2}{|c|}{$\begin{array}{l}\text { Overall } \\
(N=167,106)\end{array}$} & \multicolumn{2}{|c|}{$\begin{array}{l}\text { Resection of spinal cord tumor } \\
(N=5187)\end{array}$} & \multicolumn{2}{|c|}{$\begin{array}{l}\text { Discectomy } \\
(N=24,595)\end{array}$} & \multicolumn{2}{|c|}{$\begin{array}{l}\text { Decompression surgery } \\
(N=84,540)\end{array}$} & \multicolumn{2}{|c|}{$\begin{array}{l}\text { Arthrodesis surgery } \\
(N=52,784)\end{array}$} & \multirow{2}{*}{$\begin{array}{c}\frac{p \text {-value }}{\text { a }} \\
<0.001\end{array}$} \\
\hline & 64.1 & {$[14.3]$} & 57.1 & {$[15.8]$} & 50.2 & {$[17.0]$} & 68.2 & {$[11.3]$} & 64.8 & {$[12.8]$} & \\
\hline$\leq 49$ & 26,449 & $(15.8)$ & 1607 & $(31.0)$ & 12,395 & $(50.4)$ & 5663 & $(6.7)$ & 6784 & $(12.9)$ & $<0.001$ \\
\hline $50-59$ & 24,253 & $(14.5)$ & 993 & $(19.1)$ & 4088 & $(16.6)$ & 10,937 & $(12.9)$ & 8235 & $(15.6)$ & \\
\hline $60-69$ & 45,030 & $(26.9)$ & 1307 & $(25.2)$ & 4269 & $(17.4)$ & 23,881 & $(28.2)$ & 15,573 & $(29.5)$ & \\
\hline 70-79 & 54,107 & $(32.4)$ & 1011 & $(19.5)$ & 2902 & $(11.8)$ & 32,353 & (38.3) & 17,841 & (33.8) & \\
\hline$\geq 80$ & 17,267 & $(10.3)$ & 269 & $(5.2)$ & 941 & (3.8) & 11,706 & (13.8) & 4351 & $(8.2)$ & \\
\hline \multicolumn{12}{|l|}{ Sex } \\
\hline Male & 98,445 & $(58.9)$ & 2590 & $(49.9)$ & 15,866 & $(64.5)$ & 53,808 & $(63.6)$ & 26,181 & $(49.6)$ & $<0.001$ \\
\hline Female & 68,661 & $(41.1)$ & 2597 & $(50.1)$ & 8729 & $(35.5)$ & 30,732 & $(36.4)$ & 26,603 & $(50.4)$ & \\
\hline \multicolumn{12}{|l|}{ Level of surgery } \\
\hline Cervical & 35,042 & $(21.0)$ & 564 & $(10.9)$ & 357 & $(1.5)$ & 24,596 & $(29.1)$ & 9525 & $(18.0)$ & $<0.001$ \\
\hline Thoracic & 3582 & $(2.1)$ & 465 & (9.0) & 345 & $(1.4)$ & 822 & $(1.0)$ & 1950 & $(3.7)$ & \\
\hline Lumbosacral & 10,9669 & $(65.6)$ & 884 & $(17.0)$ & 23,266 & $(94.6)$ & 50,326 & $(59.5)$ & 35,193 & $(66.7)$ & \\
\hline Unspecified & 18,813 & $(11.3)$ & 3274 & $(63.1)$ & 627 & $(2.5)$ & 8796 & $(10.4)$ & 6116 & $(11.6)$ & \\
\hline History of cardiac disease & 12,332 & $(7.4)$ & 180 & (3.5) & 833 & $(3.4)$ & 7356 & $(8.7)$ & 3963 & $(7.5)$ & $<0.001$ \\
\hline Diabetes & 27,052 & $(16.2)$ & 453 & $(8.7)$ & 2367 & (9.6) & 15,925 & $(18.8)$ & 8307 & $(15.7)$ & $<0.001$ \\
\hline Hypertension & 32,753 & $(19.6)$ & 740 & $(14.3)$ & 2511 & $(10.2)$ & 18,947 & $(22.4)$ & 10,555 & $(20.0)$ & $<0.001$ \\
\hline History of stroke & 3807 & $(2.3)$ & 70 & $(1.3)$ & 217 & $(0.9)$ & 2337 & $(2.8)$ & 1183 & $(2.2)$ & $<0.001$ \\
\hline Hemodialysis & 3340 & $(2.0)$ & 65 & (1.3) & 147 & $(0.6)$ & 1638 & (1.9) & 1490 & $(2.8)$ & $<0.001$ \\
\hline Blood transfusion & 10,382 & $(6.2)$ & 265 & (5.1) & 100 & $(0.4)$ & 2091 & $(2.5)$ & 7926 & $(15.0)$ & $<0.001$ \\
\hline Teaching institution & 35,821 & $(21.4)$ & 2891 & $(55.7)$ & 3185 & $(12.9)$ & 16,652 & $(19.7)$ & 13,093 & $(24.8)$ & $<0.001$ \\
\hline $\begin{array}{l}\text { Length of stay, days, } \\
\text { median }[\mathrm{QQR}]\end{array}$ & 21 & [16-30] & 23 & [17-33] & 16 & [12-22] & 21 & [16-28] & 25 & [19-37] & $<0.001$ \\
\hline
\end{tabular}

${ }^{a} p$-value relating to comparison between four groups including resection of spinal cord tumor, discectomy, decompression surgery, and arthrodesis surgery $S D$ standard deviation, $I Q R$ interquartile range 
Table 2 Perioperative stroke following elective spinal surgery

\begin{tabular}{|c|c|c|c|c|c|c|c|}
\hline \multirow[b]{3}{*}{ Total } & \multicolumn{7}{|c|}{ Perioperative stroke $(N(\%))$} \\
\hline & \multicolumn{2}{|l|}{ Overall } & \multirow[t]{2}{*}{$p$-value* } & \multicolumn{2}{|c|}{ Hemorrhagic } & \multicolumn{2}{|c|}{ Ischemic } \\
\hline & $371(0.2)$ & $(0.22)$ & & 53 & $(0.03)$ & 318 & $(0.19)$ \\
\hline Age, years & & & $<0.001$ & & & & \\
\hline$\leq 49$ & 15 & $(0.06)$ & & 6 & $(0.02)$ & 9 & $(0.03)$ \\
\hline $50-59$ & 29 & $(0.12)$ & & 8 & $(0.03)$ & 21 & $(0.09)$ \\
\hline $60-69$ & 85 & $(0.19)$ & & 14 & $(0.03)$ & 71 & $(0.16)$ \\
\hline $70-79$ & 156 & $(0.29)$ & & 18 & $(0.03)$ & 138 & $(0.26)$ \\
\hline$\geq 80$ & 86 & $(0.50)$ & & 7 & $(0.04)$ & 79 & $(0.46)$ \\
\hline Sex & & & 0.23 & & & & \\
\hline Male & 207 & $(0.21)$ & & 30 & $(0.03)$ & 177 & $(0.18)$ \\
\hline Female & 164 & $(0.24)$ & & 23 & $(0.03)$ & 141 & $(0.21)$ \\
\hline Surgical procedures & & & $<0.001$ & & & & \\
\hline Resection of spinal cord tumor & 19 & $(0.37)$ & & 7 & $(0.13)$ & 12 & $(0.23)$ \\
\hline Discectomy & 16 & $(0.07)$ & & 6 & $(0.02)$ & 10 & $(0.04)$ \\
\hline Decompression surgery & 193 & $(0.23)$ & & 18 & $(0.02)$ & 175 & $(0.21)$ \\
\hline Arthrodesis surgery & 143 & $(0.27)$ & & 22 & $(0.04)$ & 121 & $(0.23)$ \\
\hline Cervical spinal surgery & 99 & $(0.28)$ & 0.008 & 13 & $(0.04)$ & 86 & $(0.25)$ \\
\hline Others & 272 & $(0.21)$ & & 40 & $(0.03)$ & 232 & $(0.18)$ \\
\hline History of cardiac disease & 60 & $(0.49)$ & $<0.001$ & 6 & $(0.05)$ & 54 & $(0.44)$ \\
\hline No history & 311 & $(0.20)$ & & 47 & $(0.03)$ & 264 & $(0.17)$ \\
\hline Diabetes & 110 & $(0.41)$ & $<0.001$ & 9 & $(0.03)$ & 101 & $(0.37)$ \\
\hline No history & 261 & $(0.19)$ & & 44 & $(0.03)$ & 217 & $(0.15)$ \\
\hline Hypertension & 129 & $(0.39)$ & $<0.001$ & 17 & $(0.05)$ & 112 & $(0.34)$ \\
\hline No history & 242 & $(0.18)$ & & 36 & $(0.03)$ & 206 & $(0.15)$ \\
\hline History of stroke & 5 & $(0.13)$ & 0.29 & 1 & $(0.03)$ & 4 & $(0.11)$ \\
\hline No history & 366 & $(0.22)$ & & 52 & $(0.03)$ & 314 & $(0.19)$ \\
\hline Hemodialysis & 15 & $(0.45)$ & 0.01 & 4 & $(0.12)$ & 11 & $(0.33)$ \\
\hline No hemodialysis & 356 & $(0.22)$ & & 49 & $(0.03)$ & 307 & $(0.20)$ \\
\hline Blood transfusion & 52 & $(0.50)$ & $<0.001$ & 9 & $(0.09)$ & 43 & $(0.41)$ \\
\hline No transfusion & 319 & $(0.20)$ & & 44 & $(0.03)$ & 275 & $(0.18)$ \\
\hline Teaching institution & 107 & $(0.30)$ & 0.001 & 17 & $(0.05)$ & 90 & $(0.25)$ \\
\hline Non-teaching institution & 264 & $(0.20)$ & & 36 & $(0.03)$ & 228 & $(0.17)$ \\
\hline
\end{tabular}

\section{Discussion}

This study had three main findings. First, the incidence of perioperative stroke during hospitalization after elective spinal surgery was $0.22 \%$. Second, resection of a spinal cord tumor was associated with increased risk of perioperative stroke compared with other procedures. Finally, resection of a spinal cord tumor was associated with a higher incidence of hemorrhage stroke. The analysis of a nationwide database enabled us to investigate the incidence of this rare but devastating complication after elective spinal surgery and to evaluate its relevant risks.

Our findings were in line with previous reports, which showed the incidence of perioperative stroke following spinal surgery was $0.05-0.1 \%[17,18]$. Smith et al. examined 108,419 procedures obtained from the Scoliosis Research Society Morbidity and Mortality database [19], which had a comparable sample size to that of our study. However, the exact incidence of postoperative stroke was not clear in that study, because the authors only reported fatal cases. To our knowledge, this study was the first report to compare the incidence of perioperative stroke following spinal surgery with different surgical procedures.

In the literature, perioperative stroke after surgery has been predominately classified as ischemic stroke [4-6]. Hemorrhagic stroke accounts for only $1 \%$ of strokes 
Table 3 Adjusted risk of perioperative stroke after elective spinal surgery

\begin{tabular}{|c|c|c|c|}
\hline & \multicolumn{3}{|c|}{ Perioperative stroke } \\
\hline & OR & $95 \% \mathrm{Cl}$ & $p$-value \\
\hline \multicolumn{4}{|l|}{ Age } \\
\hline$\leq 49$ & Reference & & \\
\hline $50-59$ & 1.61 & $0.87-2.97$ & 0.13 \\
\hline $60-69$ & 2.27 & $1.31-3.94$ & 0.004 \\
\hline $70-79$ & 3.41 & $1.91-6.07$ & $<0.001$ \\
\hline$\geq 80$ & 5.66 & $3.10-10.34$ & $<0.001$ \\
\hline \multicolumn{4}{|l|}{ Sex } \\
\hline Male & Reference & & \\
\hline Female & 0.98 & $0.78-1.23$ & 0.88 \\
\hline \multicolumn{4}{|l|}{ Surgical procedures } \\
\hline Resection of a spinal cord tumor & Reference & & \\
\hline Discectomy & 0.29 & $0.14-0.58$ & 0.001 \\
\hline Decompression surgery & 0.44 & $0.26-0.73$ & 0.001 \\
\hline Arthrodesis surgery & 0.55 & $0.34-0.90$ & 0.02 \\
\hline Cervical spinal surgery & 1.44 & $1.09-1.90$ & 0.01 \\
\hline History of cardiac disease & 1.58 & $1.10-2.26$ & 0.01 \\
\hline Diabetes & 1.73 & $1.36-2.20$ & $<0.001$ \\
\hline Hyper tension & 1.53 & $1.18-1.98$ & 0.001 \\
\hline Hemodialysis & 1.51 & $0.88-2.59$ & 0.13 \\
\hline Blood transfusion & 1.23 & $0.83-1.82$ & 0.30 \\
\hline Teaching institution & 1.36 & $1.01-1.82$ & 0.04 \\
\hline Length of stay (days) & 1.01 & $1.01-1.01$ & $<0.001$ \\
\hline
\end{tabular}

$O R$ odds ratio, $\mathrm{Cl}$ confidence interval

occurring after coronary artery bypass grafting surgery [2]. In our study, we observed a higher percentage of hemorrhagic stroke following elective spinal surgery $(14.3 \%)$, which suggested that the pathomechanism of perioperative stroke varies according to the type of surgical procedure.

The current study showed that resection of a spinal cord tumor, requiring dural incision to access the tumor, had a higher risk of perioperative hemorrhagic stroke. Although intracranial hemorrhage after spinal surgery complicated by CSF leakage has been reported [17, 22-26], the mechanism of this complication remains speculative. In the presence of CSF leakage, the postulated pathophysiology in previous case reports was that an increase in transluminal venous pressure caused by intracranial hypotension from CSF loss may have resulted in blood vessel rupture [25]. Another possibility is that downward cerebellar sag causes stretching and occlusion of the bridging cerebellar veins [34]. Further investigations are needed to clarify the mechanism of intracranial hemorrhage after spinal surgery in order to prevent this catastrophic complication.
The results of this study showed that cervical spine surgery was also associated with the risk of perioperative stroke. Although cervical spine injury was reported to be a risk factor for blunt cerebrovascular injury [28, 35-37], a large-scale study on the relationship between elective spinal surgery at the cervical region and perioperative stroke has never been reported. However, a few reports regarding the impact of prolonged retraction during cervical anterior spinal surgery on carotid artery blood flow were reported [38, 39]. Moreover, Lunardini et al. showed, in their survey of 163,324 cervical spinal surgeries, that cerebellar infarction occurred in $5.5 \%$ of patients with intraoperative vertebral artery injury [40]. Cervical spinal surgery, with a potential risk of intraoperative vertebral artery injury, may carry a higher risk for perioperative stroke.

There are a few limitations of this study. First, we were unable to investigate strokes occurring after discharge because of the lack of available data. However, according to OECD data, the national average length of hospital stay in Japan is 17.5 days, which is much longer than in other countries [41]. In Japan, hospitals often provide both early postoperative care and subsequent rehabilitation in a single hospitalization. Therefore, we believe that the follow-up period in this study, with a median of 21 days, was sufficient to detect the majority of strokes occurring after surgery, because most perioperative strokes reportedly occur within a few days after surgery. Indeed, approximately $45 \%$ of perioperative strokes are reported within the first day after surgery $[14,42]$. Second, the DPC database does not provide detailed clinical information such as severity of preoperative neurological symptoms, the level of fusion, and the presence of an incidental dural tear during spinal surgery. For instance, the DPC database does not include the "surgical level" as an entry field. In this analysis, we determined the surgical level based on the patients' primary diagnosis (i.e., patients with lumbar spinal stenosis as their primary diagnosis were designated to have had lumbar spine surgery). In addition, we were unable to definitely differentiate intradural and extradural tumors from the DPC data. However, we excluded patients with metastatic spinal tumors, which have been reported to account for around $90 \%$ of extradural spinal tumors [43, 44]. We believe the results of this study were unlikely to be affected by any unrecognized cases of extradural spinal tumor in this analysis. Third, the coded diagnoses may be less well validated than in a prospective survey because of possible misclassification or underreporting. However, we believe the rate of miscoding was relatively low because the diagnoses were recorded by the attending physicians. Finally, there may be some selection bias because of differences in participation rates between academic hospitals, which all contribute to the DPC database, and community hospitals, which only contribute voluntarily. 


\section{Conclusions}

This study revealed that perioperative stroke occurred in $0.22 \%$ of patients who underwent elective spinal surgery. Resection of a spinal cord tumor was associated with a higher risk of perioperative stroke compared with other surgical procedures as well as advanced age, comorbidities at admission, cervical spine surgery, surgery in a teaching hospital, and length of stay. We believe the findings of this study provide useful information for a better understanding of the risk of perioperative stroke following elective spinal surgery.

\section{Competing interests}

Each author certifies that they have no commercial associations that might pose a conflict of interest in connection with the submitted article.

\section{Authors' contributions}

JO, HC, KT and ST contributed to the conception and design of the study. JO, $\mathrm{HC}, \mathrm{TO}, \mathrm{HH}$, and $\mathrm{HY}$ contributed to the analysis, and all authors contributed to the interpretation of the results. JO drafted the article; all authors revised it critically and approved the final version submitted for publication. All authors read and approved the final manuscript.

\section{Authors' information}

Not Applicable.

\section{Acknowledgements}

This work was supported by grants for Research on Policy Planning and Evaluation from the Ministry of Health, Labour and Welfare, Japan (grant numbers: H27-Policy-Designated-009 and H27-Policy-Strategy-011). The funder has played no role in the design, data collection and analysis, decision to publish or preparation of the manuscript.

\section{Author details}

'Department of Orthopaedic Surgery, Faculty of Medicine, The University of Tokyo, Hongo 7-3-1, Bunkyo, Tokyo, Japan. ${ }^{2}$ Department of Health Economics and Epidemiology Research, School of Public Health, The University of Tokyo, Hongo 7-3-1, Bunkyo, Tokyo, Japan.

Received: 20 September 2014 Accepted: 29 September 2015 Published online: 02 October 2015

\section{References}

1. Hinterhuber G, Bohler K, Kittler H, Quehenberger P. Extended monitoring of hemostatic activation after varicose vein surgery under general anesthesia. Dermatol Surg. 2006;32:632-9.

2. Likosky DS, Caplan LR, Weintraub RM, Hartman GS, Malenka DJ, Ross CS, et al. Northern New England Cardiovascular Disease Study Group, Lebanon, New Hampshire. Intraoperative and postoperative variables associated with strokes following cardiac surgery. Heart Surg Forum. 2004;7:E271-6.

3. Nosan DK, Gomez CR, Maves MD. Perioperative stroke in patients undergoing head and neck surgery. Ann Otol Rhinol Laryngol. 1993;102:717-23.

4. Brooker RF, Brown WR, Moody DM, Hammon Jr JW, Reboussin DM, Deal DD, et al. Cardiotomy suction: a major source of brain lipid emboli during cardiopulmonary bypass. Ann Thorac Surg. 1998;65:1651-5.

5. Limburg M, Wijdicks EF, Li H. Ischemic stroke after surgical procedures: clinical features, neuroimaging, and risk factors. Neurology. 1998:50:895-901.

6. Restrepo L, Wityk RJ, Grega MA, Borowicz L, Barker PB, Jacobs MA, et al. Diffusion- and perfusion-weighted magnetic resonance imaging of the brain before and after coronary artery bypass grafting surgery. Stroke. 2002;33:2909-15.

7. Hogue Jr CW, Murphy SF, Schechtman KB, Davila-Roman VG. Risk factors for early or delayed stroke after cardiac surgery. Circulation. 1999;100:642-7.

8. Kam PC, Calcroft RM. Perioperative stroke in general surgical patients. Anaesthesia. 1997:52:879-83.

9. Landercasper J, Merz BJ, Cogbill TH, Strutt PJ, Cochrane RH, Olson RA, et al. Perioperative stroke risk in 173 consecutive patients with a past history of stroke. Arch Surg. 1990;125:986-9.
10. Naylor AR, Mehta Z, Rothwell PM, Bell PR. Carotid artery disease and stroke during coronary artery bypass: a critical review of the literature. Eur J Vasc Endovasc Surg. 2002;23:283-94.

11. Paramo JA, Rifon J, Llorens R, Casares J, Paloma MJ, Rocha E. Intra- and postoperative fibrinolysis in patients undergoing cardiopulmonary bypass surgery. Haemostasis. 1991;21:58-64

12. Selim M. Perioperative stroke. N Engl J Med. 2007;356:706-13.

13. Bond R, Rerkasem K, Shearman CP, Rothwell PM. Time trends in the published risks of stroke and death due to endarterectomy for symptomatic carotid stenosis. Cerebrovasc Dis. 2004;18:37-46.

14. Bucerius J, Gummert JF, Borger MA, Walther T, Doll N, Onnasch JF, et al. Stroke after cardiac surgery: a risk factor analysis of 16,184 consecutive adult patients. Ann Thorac Surg. 2003;75:472-8.

15. Gutierrez IZ, Barone DL, Makula PA, Currier C. The risk of perioperative stroke in patients with asymptomatic carotid bruits undergoing peripheral vascular surgery. Am Surg. 1987;53:487-9.

16. McKhann GM, Grega MA, Borowicz Jr LM, Baumgartner WA, Selnes OA. Stroke and encephalopathy after cardiac surgery: an update. Stroke. 2006:37:562-71.

17. Bekelis K, Desai A, Bakhoum SF, Missios S. A predictive model of complications after spine surgery: the National Surgical Quality Improvement Program (NSQIP) 2005-2010. Spine J. 2014;14:1247-55.

18. Schoenfeld AJ, Ochoa LM, Bader JO, Belmont Jr PJ. Risk factors for immediate postoperative complications and mortality following spine surgery: a study of 3475 patients from the National Surgical Quality Improvement Program. J Bone Joint Surg Am. 2011;93:1577-82.

19. Smith JS, Saulle D, Chen CJ, Lenke LG, Polly Jr DW, Kasliwal MK, et al. Rates and causes of mortality associated with spine surgery based on 108,419 procedures: a review of the Scoliosis Research Society Morbidity and Mortality Database. Spine (Phila Pa 1976). 2012;37:1975-82.

20. Wu JC, Chen YC, Liu L, Chen TJ, Huang WC, Thien PF, et al. The risk of stroke after spinal fusion surgery: a national cohort study. Spine J. 2012;12:492-9.

21. Wu JC, Chen YC, Liu L, Huang WC, Thien PF, Chen TJ, et al. Lumbar spine fusion surgery and stroke: a national cohort study. Eur Spine $J$. 2012;21:2680-7.

22. Bowers CA, Taussky P, Duhon BS, Schmidt MH. Multiple supra- and infratentorial intraparenchymal hemorrhages presenting with seizure after massive sacral cerebrospinal fluid drainage. Spine (Phila Pa 1976). 2011;36:E288-91.

23. Chauvet D, Silhouette B, Engrand N, Pradier F, Piotin M, Lot G. Multiple spinal hemangioblastomas complicated with postoperative remote cerebellar hemorrhage: review of the literature of two rare entities. World Neurosurg. 2014;81:843.e1-4. doi:10.1016/j.wneu.2012.11.054.

24. Kaloostian PE, Kim JE, Bydon A, Sciubba DM, Wolinsky JP, Gokaslan ZL, et al. Intracranial hemorrhage after spine surgery. J Neurosurg Spine. 2013:19:370-80.

25. Khalatbari MR, Khalatbari I, Moharamzad Y. Intracranial hemorrhage following lumbar spine surgery. Eur Spine J. 2012;21:2091-6.

26. Zimmermann RM, Kebaishi KM. Intracranial hemorrhage following incidental durotomy during spinal surgery. A report of four patients. J Bone Joint Surg Am. 2007;89:2275-9.

27. Akiyama T, Chikuda H, Yasunaga H, Horiguchi H, Fushimi K, Saita K. Incidence and risk factors for mortality of vertebral osteomyelitis: a retrospective analysis using the Japanese diagnosis procedure combination database. BMJ Open. 2013;3. doi:10.1136/bmjopen-2012-002412.

28. Chikuda H, Ohya J, Horiguchi H, Takeshita K, Fushimi K, Tanaka S, et al. Ischemic stroke after cervical spine injury: analysis of 11,005 patients using the Japanese diagnosis procedure combination database. Spine J. 2014;14:2275-80

29. Chikuda H, Yasunaga H, Horiguchi H, Takeshita K, Kawaguchi H, Matsuda S, et al. Mortality and morbidity in dialysis-dependent patients undergoing spinal surgery: analysis of a national administrative database in Japan. J Bone Joint Surg Am. 2012;94:433-8.

30. Chikuda H, Yasunaga H, Horiguchi H, Takeshita K, Sugita S, Taketomi S, et al. Impact of age and comorbidity burden on mortality and major complications in older adults undergoing orthopaedic surgery: an analysis using the Japanese diagnosis procedure combination database. BMC Musculoskelet Disord. 2013;14:173.

31. Chikuda H, Yasunaga $H$, Takeshita $K$, Horiguchi $H$, Kawaguchi $H$, Ohe K, et al. Mortality and morbidity after high-dose methylprednisolone treatment in patients with acute cervical spinal cord injury: a propensity-matched analysis using a nationwide administrative database. Emerg Med J. 2014;31:201-6. 
32. Masuda $\mathrm{K}$, Chikuda $\mathrm{H}$, Yasunaga $\mathrm{H}$, Hara N, Horiguchi H, Matsuda S, et al. Factors affecting the occurrence of pulmonary embolism after spinal surgery: data from the national administrative database in Japan. Spine J. 2012;12:1029-34

33. Hubbaard AE, Ahern J, Fleischer NL, Van der Laan M, Lippman SA, Jewell N, et al. To GEE or not to GEE: comparing population average and mixed models for estimating the association between neighborhood risk factors and health. Epidemiology. 2010;21:467-74.

34. Andrews RT, Koci TM. Cerebellar herniation and infarction as a complication of an occult postoperative lumbar dural defect. Am J Neuroradiol. 1995;16:1312-5.

35. Inamasu J, Guiot BH. Vertebral artery injury after blunt cervical trauma: an update. Surg Neurol. 2006;65:238-45.

36. Miller PR, Fabian TC, Croce MA, Cagiannos C, Williams JS, Vang M, et al. Prospective screening for blunt cerebrovascular injuries: analysis of diagnostic modalities and outcomes. Ann Surg. 2002;236:386-93.

37. Mutze $S$, Rademacher $G$, Matthes $G$, Hosten N, Stengel D. Blunt cerebrovascular injury in patients with blunt multiple trauma: diagnostic accuracy of duplex Doppler US and early CT angiography. Radiology. 2005;237:884-92.

38. Chozick BS, Watson P, Greenblatt SH. Internal carotid artery thrombosis after cervical corpectomy. Spine (Phila Pa 1976). 1994;19:2230-2.

39. Yeh $Y C$, Sun $W Z$, Lin CP, Hui CK, Huang IR, Lee TS. Prolonged retraction on the normal common carotid artery induced lethal stroke after cervical spine surgery. Spine (Phila Pa 1976). 2004;29:E431-4.

40. Lunardini DJ, Eskander MS, Even JL, Dunlap JT, Chen AF, Lee JY, et al. Vertebral artery injuries in cervical spine surgery. Spine J. 2014;14:1520-5.

41. OECD. Average length of stay in hospitals. In: Health at a Glance 2013. OECD Indicators. OECD Publishing; 2013. http://dx.doi.org/10.1787/ health_glance-2013-36-en. Accessed 27 Aug 2015.

42. Likosky DS, Marrin CA, Caplan LR, Baribeau YR, Morton JR, Weintraub RM, et al. Determination of etiologic mechanisms of strokes secondary to coronary artery bypass graft surgery. Stroke. 2003;34:2830-4.

43. Avila EK, Elder JB, Singh P, Chen X, Bilsky MH. Intraoperative neurophysiologic monitoring and neurologic outcomes in patients with epidural spine tumors. Clin Neurol Neurosurg. 2013;115:2147-52.

44. Lam FC, Arle JE, Glazer PA, Kasper EM. Primary extradural tumors of the spine - case review with evidence-guided management. Surg Neurol Int. 2014;5:S373-5.

\section{Submit your next manuscript to BioMed Central and take full advantage of:}

- Convenient online submission

- Thorough peer review

- No space constraints or color figure charges

- Immediate publication on acceptance

- Inclusion in PubMed, CAS, Scopus and Google Scholar

- Research which is freely available for redistribution 